\title{
KOFAT $^{\odot}$ AS AN ALTERNATIVE SOURCE OF FAT IN BROILER DIETS
}

(Received:26.3.2009)

\author{
By \\ A. Abudabos \\ Department of Animal Production, Faculty of Agriculture, Mutah University, Karak, Jordan
}

\begin{abstract}
A study was conducted to investigate the effect of $\operatorname{Kofat}^{\circledR}$ as the fat source on the performance of one strain of broiler. A total of $4801 \mathrm{~d}$ old Lohamn chicks was obtained from a commercial hatchery and placed in 8 pens. Two corn-soy diets were introduced, one contained soy-oil while the other contained $\mathrm{Kofat}^{\oplus}$, as a source of fat in the diet. Each diet was assigned to 4 pens with 60 chicks in each. The experiment lasted 6 weeks. Data were subjected to ANOVA for a randomized complete block design. Feed conversion, average daily gain and feed consumption were not significantly affected by fat source $(\mathrm{P}>0.05)$. Also, parts yield, abdominal fat and cooking loss were not significantly affected by the treatment $(\mathrm{P}>0.05)$. Including $\mathrm{Kofat}^{\Theta}$ as a fat source of broiler diet resulted in the same performance as those contained soy oil but with low cost. $\mathrm{Kofat}^{\Theta}$ will make an excellent fat source for broiler diet from 1 $\mathrm{d}$ old until marketing age.
\end{abstract}

Key words:abdominal fat, chicken abdominal fat, fat, Kofat, performance,

\section{INTRODUCTION}

Lipid constitutes the main energy source of poultry deits and it has the highest caloric value among all nutrients. Fats are used in broiler diet to increase the energy density. The addition of fat or oil to grower diets can improve feed efficiency and increase digestibility in broiler (Coon et al., 1981). The value of various fats or oils depends on price, ME contents, digestibility and absorption (Waldroup et al., 1995).

Fats used in poultry diets such as tallow or vegetable oils (soybean oil, rapeseed oil, coconut oil or corn oil) depend on the cost or location, where these oils are available. Vegetable oil such as soybean oil, sunflower oil or cottonseed oil are the major sources of supplemental fat available for use in poultry diets in the Middle East (Barbour et al., 2006).

The high cost of supplemental energy necessitates the optimization of fat inclusion in the diets especially during the finisher period where the feed consumption is the greatest. There is also a trend toward using oils from plant origin rather than using animal by-product sources in poultry diets. So, the demand is great toward feeding low-price, vegetable fat sources.

Kofat $^{\Theta}$ is formulated from a mixture of various vegetable oils and is used as a supplement in animal feeds as a source of fat. Therefore, the objective of present study was to evaluate the effect of $\mathrm{Kofat}^{\odot}$ as an alternative fat source on the performance and carcass quality of broiler chickens.

\section{MATERIALS AND METHODS}

\subsection{Birds and management}

Four hundred and eighty one day-old Lohamn broiler chicks were obtained from a commercial hatchery and randomly distributed among 8 floor pens with wood shavings with 60 chicks per pen. All pens had similar average of starting live body weight. The birds were reared in a conventional poultry house with raised side windows. The birds were maintained a $24 \mathrm{~h}$ light schedule.

\subsection{Diets and experimental design}

Isocaloric and isonitrogenous corn-soybean meal diets were formulated to contain either soy oil or Kofat ${ }^{\Theta}$ as the source of fat in the diet (Table 1). Starter diet was fed from 1 to 21 day old, contained $21 \% \mathrm{CP}$ and $3058 \mathrm{kcal}$ of $\mathrm{ME} / \mathrm{kg}$. Finisher diet (22 to 42 day old) contained CP and ME were $19 \%$ and $3140 \mathrm{kcal} / \mathrm{kg}$, respectively. Feed and water were provided ad- libitum.

Treatments were followed a randomized complete block design, in which each experimental diet was fed to 4 replicate pens. The experimental unit was the pen mean. Significant treatment effects were determined using ANOVA. All analyses were conducted with general linear model procedure of SAS ${ }^{\circledR}$ Software (SAS Institute, 1992). 


\subsection{Measurements}

Body weight and feed consumption were recorded by pen at 21,35 , and 42 days of age. Feed conversion was computed. At the end of the experiment, representative males per pen were selected, weighed, and slaughtered. All viscera, abdominal fat, shanks and heads were removed. Parts of yield and abdominal fat were weighed and recorded (Izat et al., 1990). The left pectoralis muscles were deboned and weighed for cooking losses measurements.

Table (1): Composition and calculated analysis of experimental diets.

\begin{tabular}{|c|c|c|c|c|}
\hline & \multicolumn{2}{|c|}{ Starter diet } & \multicolumn{2}{|c|}{ Finisher diet } \\
\hline & Diet1 & Diet 2 & Diet1 & Diet2 \\
\hline \multicolumn{5}{|l|}{ Ingredients $(\mathrm{g} / \mathrm{kg})$} \\
\hline Corn yellow & 605.2 & 605.2 & 658.3 & 658.3 \\
\hline $\begin{array}{l}\text { Soybean meal (48\% } \\
\text { CP) }\end{array}$ & 330.0 & 330.0 & 280.0 & 280.0 \\
\hline Soybean oil & 25.0 & - & 28.0 & - \\
\hline Kofat $^{\mathcal{O}}$ & - & 25.0 & - & 28.0 \\
\hline $\mathrm{NaCl}$ & 3.0 & 3.0 & 3.0 & 3.0 \\
\hline Limestone & 7.2 & 7.2 & 7.2 & 7.2 \\
\hline $\begin{array}{l}\text { Di Calcium } \\
\text { phosphate }\end{array}$ & 23.0 & 23.0 & 17.0 & 17.0 \\
\hline DL-methionine & 1.6 & 1.6 & 1.5 & 1.5 \\
\hline $\begin{array}{l}\text { Vitamin-mineral } \\
\text { premix }^{1}\end{array}$ & 3.0 & 3.0 & 3.0 & 3.0 \\
\hline Amprol & 0.5 & 0.5 & 0.5 & 0.5 \\
\hline Choline chloride & 1.5 & 1.5 & 1.5 & 1.5 \\
\hline \multicolumn{5}{|l|}{ Calculated analysis } \\
\hline CP (\%) & 21 & 21 & 19 & 19 \\
\hline ME (Kcal/Kg) & 3050 & 3050 & 3140 & 3140 \\
\hline Methionine (\%) & 0.51 & 0.51 & 0.48 & 0.48 \\
\hline $\begin{array}{l}\text { Methionine + Cystine } \\
(\%)\end{array}$ & 0.90 & 0.9 & 0.78 & 0.78 \\
\hline Lysine & 1.10 & 1.1 & 1.0 & 1.0 \\
\hline Linoleic acid & 2.80 & 1.96 & 3.07 & 2.12 \\
\hline Calcium & 1.0 & 1.0 & 0.85 & 0.85 \\
\hline A.V. Phosphorus & 0.45 & 0.45 & 0.35 & 0.35 \\
\hline
\end{tabular}

${ }^{1}$ Amount supplied per Kilogram of diet : calcium carbonate, $1.32 \mathrm{~g}$ (calcium, $0.5 \mathrm{~g}$ ); vitamin A (retinyl acetate), 186.000IU ; vitamin D3 (cholecalaiferol), 3.720 ICU vitamin $\mathrm{E}(\mathrm{DL}-\dot{\alpha}$-tocopheryl acetate), 33.000IU; vitamin $\mathrm{k}$ (menadione sodium bisulfide), $5.4 \mathrm{mg}$; vitamin B1, 2.7mg; vitamin B2, $6.6 \mathrm{mg}$ vitamin $\mathrm{B} 12,1.65 \mathrm{mg}$; niacin, $53.1 \mathrm{mg}$; folic acid , $1.65 \mathrm{mg}$;pantothenic acid (calcium D-pantothenate) $15.9 \mathrm{mg}$ D-biotin, $6.6 \mathrm{mg}$; choline ,chloride , 300mg vitamin C 100mg ; butylated hydroxytoluene , $150 \mathrm{mg}$; $108 \mathrm{mg}$;iron, $102 \mathrm{mg}$; zinc, $77.4 \mathrm{mg}$ copper, $16.1 \mathrm{mg}$; cobalt $0.16 \mathrm{mg}$; iodine $0.60 \mathrm{mg}$; and selenium, 0.4

\section{RESULTS AND DISCUSSION}

The effect of oil source added in broiler diets on feed efficiency and growth are shown in Table 2. The amount of feed consumed by birds and their body weight gain were not significant $(\mathrm{P}>0.05)$. As a result, feed efficiency conversion was similar among the two treatments at 21,35 and $42 \mathrm{~d}$ of age.

Similar response was obtained by Valencia et al. (1993) who reported that there were no effects of the sources of oil (refined palm oil, palm oil, corn oil and poultry fat) on weight gain and feed conversion of broilers.

The effect of fats on live performance of broilers is well documented. It was reported that by increasing the proportion of supplemental animal-vegetable blend fat from 0 to $60 \mathrm{~g} / \mathrm{kg}$ in an isocaloric diets, feed conversion was improved without any effects on the body weight, feed intake, carcass composition, or abdominal fat (Girffiths et al., 1997). Growth stimulating property of oil is not just a result of their high energy value, chicks fed diets with soybean oil or corn oil consumed more ME than chicks fed comparable diets that had low fat content (Carew et al., 1963).

The value of the various fats and oils is entirely dependent on their ME contents, and the ME content of the fat should be dependent on their digestibility and absorption which are greatly dependent on their fatty acid content. . In this experiment, birds received the two dietary treatments had similar live performance; this led to the conclusion that the two fat sources have similar digestibility and absorbability rate.

Carcass parameters of broiler chickens fed the two dietry treatments are shown in Table (3). Treatment had no significant effects on dressing percentage, breast yield, leg quarter yield, abdominal fat or cooking loss $(\mathrm{P}>0.05)$.

Due to the high cost of feed ingredient for poultry especially dietary energy, it is important to continually evaluate the source as well as the level of energy in the diets (Pesti et al., 2002). Fat or oil supplementation occurs with major adjustments in corn and soybean meal level (Deaton et al., 1981). Supplementing the diets with fat source maybe more cost effective over the finisher period because of increased digestibility of fat and improved of dietary ME (Wiseman and Salvador 1989). $\operatorname{Kofat}^{\oplus}$ is a cheaper source of fat compared to soybean oil or corn oil. 
Table (2): Effect of oil source on body weight (BW), feed consumption and feed conversion (FC) of broilers at different ages.

\begin{tabular}{|c|c|c|c|c|}
\hline \multicolumn{5}{|c|}{ Treatment } \\
\hline Age & $\begin{array}{c}\text { Soybean } \\
\text { oil }\end{array}$ & Kofat $^{\odot}$ & S.E. & P-value \\
\hline \multicolumn{5}{|c|}{$\mathbf{2 1 ~ d}$} \\
\hline BW(g) & 690 & 691 & \pm 5.0 & N.S \\
\hline Feed (g) & 1161.8 & 1108.4 & \pm 22.7 & N.S \\
\hline FC(g: g) & 1.683 & 1.603 & \pm 0.027 & N.S \\
\hline \multicolumn{5}{|c|}{$35 d$} \\
\hline BW(g) & 1770 & 1796 & \pm 47.0 & N.S \\
\hline Feed (g) & 3306 & 3229 & \pm 52.3 & N.S \\
\hline FC (g: g) & 1.870 & 1.798 & \pm 0.049 & N.S \\
\hline \multicolumn{5}{|c|}{42 d } \\
\hline BW(g) & 2247 & 2177 & \pm 38.2 & N.S \\
\hline Feed (g) & 4401 & 4352 & \pm 89.0 & N.S \\
\hline FC (g: g) & 1.95 & 2.000 & \pm 064 & N.S \\
\hline
\end{tabular}

The effect of fat and vegetable oil needs to be examined not only for production characteristics but also for meat quality and blood parameters relative to human health (Ozdogan and Aksit, 2003). The results of the present study indicate that there was no differences in meat measurements (Table 3). Kofat ${ }^{\odot}$ is formulated from a mixture of various vegetable oils supplemented with anti-oxidant and lecitain. The profile of fatty acids is of important to the quality of the utilized lipid, the absorption of these lipids, by and the quality of the fat deposited on the carcass. The fatty acid composition profile of $\mathrm{Kofat}^{(}$is as follows: Myristic acid (C14:0) 6.0, palmitic acid (C16:0) 30-35, stearic acid (18:0) 4.0-5.0, oleic acid (C18:1) 35.0-42.0, and linoleic acid (C18:2) 16-20\%. In this study there was no significant effect of fat source on abdominal fat $(\mathrm{P}>0.05)$. The location of fat deposition depends on the kind of fatty acid that added to the diet (saturated and polyunsaturated). Birds fed diets rich of animal saturated fatty acids tend to have proportionally larger abdominal and mesenteric fat than other fat deposits (Deaton et al., 1981).

It can be concluded that the replacement of soybean oil or corn oil with $\mathrm{Kofat}^{\ominus}$ resulted in good performance in terms of body weight, feed utilization, carcass characteristics for broilers while using $\mathrm{Kofat}^{\circ}$ as a fat source resulted in lowering the feed cost based on the fact that the cost of $\mathrm{Kofat}^{\oplus}$ is $\$ 200 /$ ton compared with soy oil.

Table (3): Effect of oil source on dressing characteristics of male broiler at $42 \mathrm{~d}$ of age.

\begin{tabular}{|l|c|c|c|c|}
\hline \multicolumn{1}{|c|}{ Treatments } \\
\hline Character & $\begin{array}{c}\text { Soybean } \\
\text { oil }\end{array}$ & Kofat $^{\odot}$ & S.E & P. value \\
\hline Dressing (\%) & 70.12 & 70.3 & \pm 0.21 & N.S \\
\hline $\begin{array}{l}\text { Breast yield (\% of } \\
\text { dressed weight) }\end{array}$ & 20.6 & 20.5 & $\begin{array}{c} \pm 0.12 \\
4\end{array}$ & N.S \\
\hline $\begin{array}{l}\text { Leg quarter yield } \\
\text { (\% of dressed } \\
\text { weight) }\end{array}$ & 33.93 & 33.95 & \pm 0.13 & N.S \\
\hline $\begin{array}{l}\text { Abdominal fat (\%) } \\
\text { of dressed weight) }\end{array}$ & 2.35 & 2.48 & \pm 0.64 & N.S \\
\hline Cooking loss (\%) & 26.33 & 26.55 & \pm 0.23 & N.S \\
\hline
\end{tabular}

(Means of four replicate pens of 2 male per replicate)

\section{REFERENCES}

Barbour G.W., Farran M. T., Usayran N.N., Darwish A.H. and Ashkarian V.M. (2006). Effect of soybean oil supplementation to low metabolizable energy diets on production parameters of broiler chickens. J. Appl. Poult. Res., 15:190-197.

Carew L.B. Jr., Nesheim M.C. and Hill F.W. (1963). The relationship of dietary energy level and density to the growth response of chicks to fats. Poult. Sci.,42:710-718.

Coon C.N., Becker W.A. and Spencer J.V. (1981). The effect of feeding high energy diets containing supplemental fat on broiler weight gain, feed efficiency and carcass composition. Poult. Sci.,60:1264-1271.

Deaton J.W., McNaughton J.L., Reece F.N. and Loot B.D. (1981). Abdominal fat of broilers as influenced by dietary level of animal fat. Poult. Sci.,60:1250-1253.

Griffiths L., Leeson S.and Summers J.D. (1977). Influence of energy system and level of various fat sources on performance and carcass composition of broiler. Poult. Sci., 56:1018-1026.

Izat A.L., Colberg M., Reiber M.A., Adams M.H., Skinner J.T., Cabel M.C., Stilborn H.L. and Waldroup P.W. (1990). Effects of different antibiotics on performance, processing characteristics, and parts yield of broiler chickens. Poult. Sci., 69:17871791. 
National Research Council. (1994). Nutrient Requirements of Poultry. $9^{\text {th }}$ rev. ed. Natl. Acad. Press, Washington, DC.

Ozdogan M. and Aksit M. (2003). Effects of feed containing different fat on carcass and blood parameters of broilers. J. Appl. Poult Res.,12:251-256.

Pesti G. M., Bakalli R.I., Qiao M. and Sterling K.G. (2002). Comparison of eight grades of fat as broiler feed ingredients. Poult. Sci.,81:382-390.

SAS Users Guide. (1992).Version 5 ed. SAS Inst. Inc., Cary, NC.
Valencia M.E.,Watkins S.E., Waldroup A.L. and Waldroup P.W. (1993). Utilization of crude and refined palm and palm kernel oils in broiler diets. Poult. Sci., 72: 2200-2215.

Waldroup A.L., Watkins S.E. and Saleh E.A. (1995). Comparison of two blended animalvegetable fats having low or high free fatty acid content. J. Appl. Poult. Res., 4:41-48.

Wiseman J. and Salvador F. (1989). Influence of age, chemical composition and rate of inclusion on the apparent metabolizable energy of fats fed to broiler chicks. Br. Poult. Sci.,30:653-662.

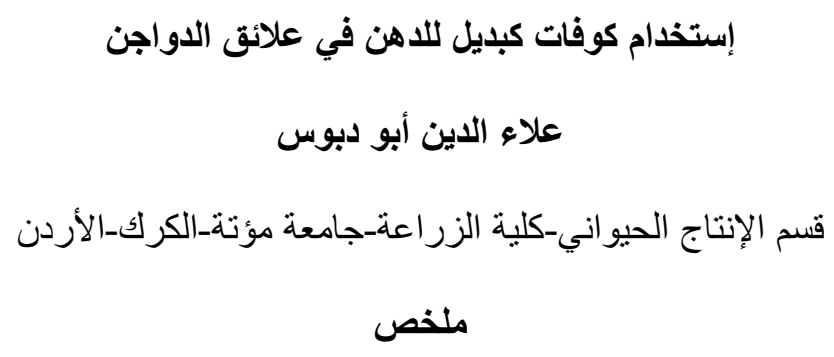

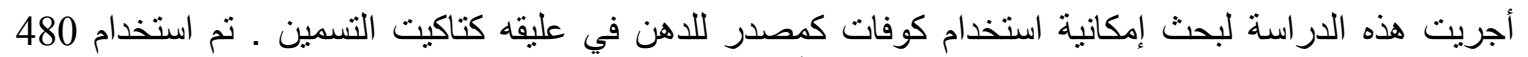

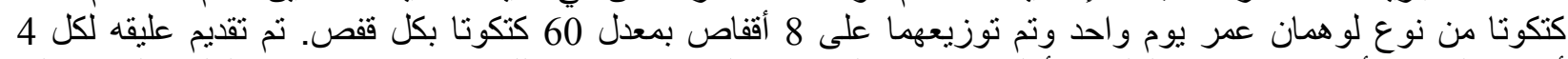

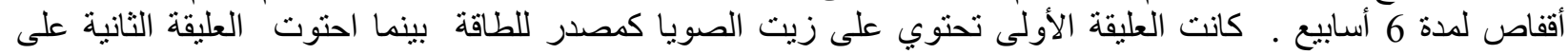

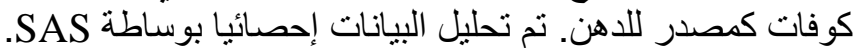

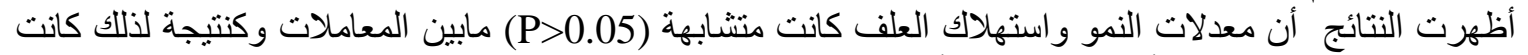

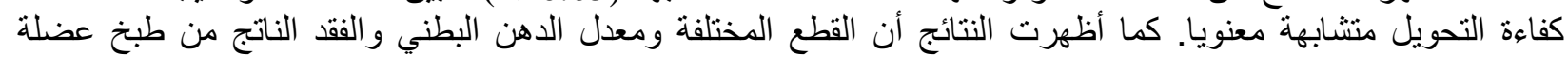

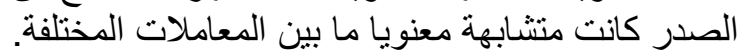

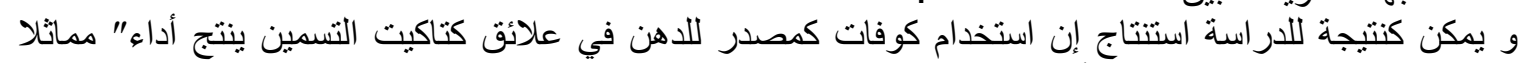

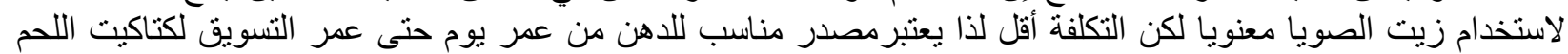

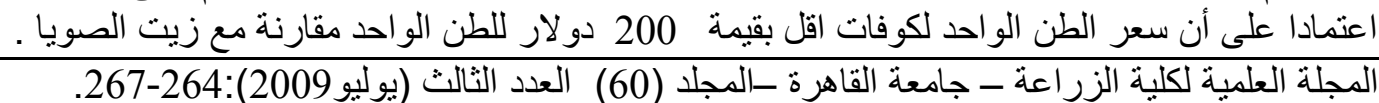

